\title{
AMBIENTE NATURAL E O IMAGINÁRIO: MAR, DESERTO, MATA E CHUVA EM REPRESENTAÇÕES PICTÓRICAS NA EDUCAÇÃO INFANTIL
}

\author{
Ana Gabriela da Silva Rocha ${ }^{1}$ \\ Rossano André Dal-Farra²
}

Resumo: A educação infantil se constitui na base da formação do sujeito no que tange à interação com o ambiente. Com base nesta premissa, o presente estudo apresenta o trabalho realizado em uma escola localizada no Rio Grande do Sul voltado à percepção da natureza dos estudantes. Foram analisadas representações pictóricas de mar, deserto, mata e chuva e os relatos das crianças por meio da Estatística Descritiva e análise qualitativa das falas dos alunos sobre os desenhos. Os resultados proporcionaram caracterizar o olhar dos alunos a respeito dos ambientes e as dificuldades de percepção do papel do ser humano na natureza, assim como a relevância das falas das crianças a respeito de suas representações pictóricas, evidenciando a importância de práticas educativas desta natureza na Educação Ambiental.

Palavras-chave: Educação Infantil; Educação Ambiental; Representação Pictórica

Abstract: Early childhood education is the basis of the formation of the subject in terms of interaction with the environment. Based on this premise, this study presents the study in a school located in Rio Grande do Sul focused on the perception of the nature. Pictorial representations of sea, desert, forest and rain were analyzed, as well as the reports of the children through the Descriptive Statistics and qualitative analysis of the speech of the students about the drawings. The results provided a characterization of the view about the environment and the difficulties in perceiving the role of the human being in nature, as well as the relevance of the statements related to their pictorial representations, highlighting the importance of educational practices of this nature in environmental education.

Keywords: Childhood Education; Environmental Education; Pictorial Representation.

\footnotetext{
1 Universidade Luterana do Brasil. E-mail: anagabrieladasilvarocha@yahoo.com.br

2 Universidade Luterana do Brasil. E-mail: rossanodf@gmail.com
} 


\section{Introdução}

A crescente urbanização de nossas cidades tem gerado novas configurações nas paisagens visualizadas diariamente pela população. $O$ predomínio do ambiente construído, a destruição das áreas nativas e a escassez de contato dos estudantes com a natureza tem repercutido nas percepções de ambiente de nossos alunos, demandando um processo reflexivo profundo por parte de educadores que atuam nesta área da educação formal (MILLER, 2005; STERN et al., 2014).

Diante deste cenário, as práticas educativas realizadas no ambiente da educação formal voltadas à Educação Ambiental têm demonstrado o distanciamento da população em relação aos elementos bióticos comumente observado em suas regiões, assim como possuem contato remoto com locais caracterizados pela abundância de vegetação e, mais ainda, com animais nativos (PROENÇA et al., 2017; LOUREIRO; DAL-FARRA, 2018).

Diante de uma alarmante desvinculação das crianças com a natureza, gerando o que Louv (2008) chega a denominar de déficit de natureza, as preocupações com essa temática gestaram a pesquisa durante seis meses em uma escola comunitária da Região Metropolitana de Porto Alegre com atividades vinculadas às representações pictóricas de diferentes espaços do entorno.

No presente artigo, encontra-se um recorte do processo educacional realizado com o foco na produção de desenhos relacionados ao mar, ao deserto, à mata e à chuva analisados por meio das falas dos alunos e dos elementos quantitativos extraídos dos desenhos. As análises geraram um conjunto de interpretações a respeito dos principais elementos percepcionais dos estudantes em relação ao ambiente natural, gerando consistentes subsídios para a produção de práticas educativas no ensino de ciências e suas relações com os amplos domínios dos saberes relevantes para a educação infantil. Tais atividades proporcionam a construção de práticas educativas profícuas para a educação infantil por meio da concretude e da expressão do imaginário dos alunos no que tange ao ambiente natural (MORAES, 1992; TUNNICLIFFE; REIS, 2002; OTERO et al., 2003; ROCHA et al., 2015; 2016).

\section{Representações Pictóricas na Educação Infantil}

Entende-se por Educação Infantil a atividade que possui jornada mínima de quatro horas diárias e tempo integral com duração igual ou superior a sete horas diárias, compreendendo o tempo total que a criança permanece na instituição. Suas propostas pedagógicas precisam ser construídas com base em princípios éticos e estéticos objetivando garantir à criança o desenvolvimento de processos de apropriação, renovação e articulação de conhecimentos e aprendizagens (BRASIL, 2010).

De acordo com as Diretrizes Curriculares Nacionais para a Educação Infantil, (BRASIL, 2010) para que alcancem seus objetivos propostos, a escola deve proporcionar em seu espaço de trabalho, por meio de seus docentes, 
condições para um trabalho coletivo e devem assegurar em todos os aspectos o cuidado com as crianças; a promoção do desenvolvimento motor, afetivo, cognitivo, linguístico, ético, estético e sociocultural; propiciar diálogo entre escola e comunidade escolar; promover interações entre diferentes faixas etárias; trabalhar as diferentes culturas; possuir currículo adequado que proporcione experiências sensoriais e expressivas; possibilitar o desenvolvimento da autonomia da criança e incentivar a curiosidade, a exploração, o encantamento, e questionamentos relacionados ao mundo físico e social, ao tempo e à natureza.

No que diz respeito às Artes Visuais, estas são concebidas como uma linguagem com estrutura e características próprias na qual a aprendizagem decorre da articulação entre (BRASIL, 1998):

- fazer artístico - relacionado à expressão e comunicação de produção de trabalhos artísticos por meio da prática propiciando 0 desenvolvimento de processos de criação pessoal.

- apreciação - percepção do sentido que o objeto propõe articulando elementos da linguagem visual com os materiais e suportes utilizados com o objetivo de desenvolver a capacidade de construção de sentido, reconhecimento, análise e identificação de obras de arte.

- reflexão - consiste no pensar sobre os componentes do objeto artístico manifesto nas práticas educativas, compartilhando questionamentos e afirmações.

No estudo em questão concentramos a pesquisa no fazer artístico e na reflexão, uma vez que os alunos participantes do trabalho criaram suas representações a partir da sua imaginação e percepção de ambientes específicos. O processo de reflexão aconteceu em cada momento em que as crianças tiveram que lembrar-se do ambiente natural em questão para desenhá-lo e novamente quando foi necessário explicá-lo aos pesquisadores.

De forma mais ampla, a importância das representações pictóricas é reconhecida por inúmeros estudos, seja na sua produção, seja na sua utilização em práticas educativas das mais diversas formas (FANARO et al., 2005).

\section{Educação Ambiental na Educação Infantil}

Diante da complexidade envolvida na questão ambiental, destacam-se as diferentes dimensões das práticas educativas possíveis a serem aplicadas no processo educativo, incluindo as questões sociais e econômicas especialmente nos países em desenvolvimento, a conservação e gestão dos recursos naturais para o desenvolvimento, o fortalecimento da comunidade para a participação nos processos decisórios e os meios de implementação das ações para programas e projetos orientados para a sustentabilidade (PLATAFORMA AGENDA 2030, 2019). 
Ao longo das três últimas décadas, munidos dos princípios estatuídos pelas conferências relacionadas ao ambiente, desdobraram-se inúmeras ações e publicações vinculadas às práticas de Educação Ambiental e foram construídas práticas educativas que visavam à escolarização destes preceitos aplicados em sua transversalidade, tal como defendido nos parâmetros curriculares brasileiros e que, dessa forma, podem ser trabalhados na formação de professores (DAL-FARRA e VALDUGA, 2012; PROENÇA et al., 2017).

Conforme a Lei no 9.795, de 27 de abril de 1999 em seu artigo terceiro, a Educação Ambiental deve ser trabalhada em todos os níveis de ensino:

I - ao Poder Público, nos termos dos arts. 205 e 225 da Constituição Federal, definir políticas públicas que incorporem a dimensão ambiental, promover a Educação Ambiental em todos os níveis de ensino e o engajamento da sociedade na conservação, recuperação e melhoria do meio ambiente (BRASIL, 1999).

$\mathrm{Na}$ rede de dimensões envolvidas na Educação Ambiental, tal como pontua (CARVALHO, 2006) há os seguintes âmbitos:

- Educação Ambiental comportamental: a educação como agente difusor dos conhecimentos sobre meio ambiente, e indutora da mudança dos hábitos e comportamentos considerados predatórios para hábitos e comportamentos compatíveis com a preservação dos recursos naturais.

- Educação Ambiental política: a educação como formadora de sujeitos politicamente instrumentalizados para a ação criticamente embasada.

Weissman (2004) classifica as práticas de Educação Ambiental em três vertentes:

- naturalista que é centrada na pesquisa e na compreensão dos diferentes aspectos do meio ambiente.

- ambientalista que promove conservação, a proteção, o respeito ao ambiente através da compreensão, da sensibilização, da conscientização e capacitação das pessoas.

- desenvolvimento sustentável que está centrado na mudança social com posturas de caráter diverso de acordo com as condições culturais e sociais do local.

Embora estas não sejam excludentes e caracterizem, com maior frequência, olhares que podem estar combinados ponderadamente em doses distintas em cada sujeito e nas concepções predominantes de cada comunidade. $\mathrm{Na}$ contemporaneidade, com a vida urbana distante do ambiente natural (MILLER, 2005) estamos desenvolvendo em nossas crianças uma percepção limitada da natureza (LOUREIRO; DAL-FARRA, 2018), especialmente se considerarmos 0 desconhecimento que adolescentes possuem de muitas espécies que coabitam os nossos espaços de convivência, assim como das dimensões conceituais que os qualificam como nativos ou exóticos (PROENÇA et al., 2017). 
Portanto, ao examinarmos as características definidas por Weissman (2004) e confrontando-as com o que percebemos nas crianças e adolescentes, compreendemos que inicialmente a questão crucial é ampliarmos as percepções delas em relação ao ambiente, assim como sensibilizá-las em relação aos benefícios do contato com animais e plantas diretamente no seu habitat.

Outro aspecto a ser considerado se refere ao fato de parte das espécies serem consideradas como nocivas ou mesmo "feias", especialmente insetos, aracnídeos e outros invertebrados. Mesmo que seja necessário, dentro da ampliação dos saberes das crianças, reconhecer animais e plantas que a podem prejudicar, tal aspecto se constitui em parte do todo que representa o conhecimento e a maior percepção do ambiente em que vivemos, especialmente em relação aos insetos em suas representações na cultura ocidental (LAURENT, 1997; LOPES, 2014).

Diante de tal complexidade, o processo de ensino e aprendizagem da Educação Ambiental decorre da construção de práticas educativas que proporcionem ao estudante as possibilidades de leitura de mundo, através do contato, da experiência e principalmente da exploração e conhecimento do ambiente. É pela exploração que a criança gradativamente vai aumentando seu autoconhecimento e, por extensão, seu conhecimento de mundo (MORAES, 1992; CARRARO, 1997).

Em que pese as alusões a esse aspecto, há escassas contribuições voltadas especificamente para a educação infantil no que tange a saberes específicos das ciências da natureza desafiando os professores a construir práticas educativas adequadas para trabalhar dimensões distintas como os conhecimentos, valores e procedimentos que possam contribuir para a transposição didática de conteúdos (CHEVALLARD, 1988; CLEMÉNT, 2006) cuja aspereza, em alguns casos, demanda adaptações drásticas no sentido de coadunar os conhecimentos com as necessidades, anseios e características do desenvolvimento infantil (ROCHA et al., 2015).

Por tais razões o presente estudo e sua continuidade tem buscado, a partir do desenvolvimento de práticas interdisciplinares a construção de saberes ambientais em crianças cuja urbanidade as torna praticamente ausentes de contato com matas nativas, ambientes de reduzida intervenção antrópica ou mesmo que possuam árvores em profusão e disponíveis para o contato direto..

\section{Metodologia}

O conjunto de atividades foi realizado ao longo de seis meses em uma turma de alunos da educação infantil intercaladas com as demais práticas educativas regulares desenvolvidas e aplicadas com os estudantes. $O$ foco do estudo foi a questão ambiental no que se refere à percepção dos 16 estudantes em relação ao ambiente natural e o ambiente construído. Nesta perspectiva foram realizadas diferentes representações pictóricas pelas crianças retratando 
diferentes locais, tais como, o quintal da escola, uma praça próxima ao local e outros contextos a partir do imaginário dos participantes que frequentavam uma escola de educação infantil comunitária situada na Região Metropolitana de Porto Alegre (RS). Todas as atividades foram autorizadas pelos pais ou responsáveis.

Os desenhos, após finalizados, eram explicados pelas crianças para que houvesse a compreensão do significado de cada objeto apresentado. A análise foi centrada tanto na presença de elementos, quanto em sua ausência, de acordo com a pertinência de cada um no contexto representado pelo aluno. Inicialmente as crianças representaram o pátio da escola antes e após um passeio pelo local. Os resultados a preponderância de elementos do ambiente construído, especialmente o "playground", com reduzida presença da vegetação do local ou mesmo de possíveis animais, tais como insetos e pássaros encontrados naquele espaço (ROCHA et al., 2015). Posteriormente foi realizada a produção de desenhos de uma praça nas proximidades da escola, também previamente e após a visita ao local, com resultados semelhantes ao processo anterior, ou seja, com escassa representação de elementos bióticos, tais como as árvores e as aves que lá transitam (ROCHA et al., 2016).

Diante de tais resultados e com a precípua preocupação de sensibilizar os estudantes em relação ao ambiente e com o objetivo de identificar a percepção dos alunos, foi solicitado que eles realizassem desenhos representativos do mar, da mata, do deserto e da chuva. A fim de descobrir os conhecimentos prévios da turma referente a estes elementos realizamos uma roda dialogada onde foram feitas algumas perguntas aos alunos, tais como as seguintes: "O que é o mar? "; "Quem vive nele? "; "O mar é natureza?".

Em seguida, o primeiro desenho foi realizado com os alunos expressando "o que eles imaginavam ser", e "quem eles pensavam viver no mar". Esta atividade foi realizada também a respeito do deserto e da mata, com o objetivo de verificar, para cada forma de ambiente, o que os alunos relacionam a eles, de acordo com aquilo que percebem.

No encontro seguinte a atividade foi relacionada à chuva. Junto à produção dos desenhos houve uma conversa com as crianças relacionada ao tema da atividade. Os questionamentos foram: "O que é a chuva?"; "A chuva faz parte da natureza?".

Os dados foram analisados por meio dos métodos mistos com base na integraçao entre as ferramentas da Estatística Descritiva e das falas dos estudantes em um Design Convergente (CRESWELL; PLANO CLARK, 2011; DAL-FARRA; FETTERS, 2017). 


\section{Resultados e Discussão}

Os dados a seguir correspondem ao terceiro encontro com as crianças onde foram realizadas representações sobre o mar, o deserto e a mata a partir daquilo que os alunos conheciam e/ou imaginavam sobre os ambientes. A Figura 1 apresenta os resultados obtidos com os elementos representados nas produções pictóricas relacionadas ao mar:

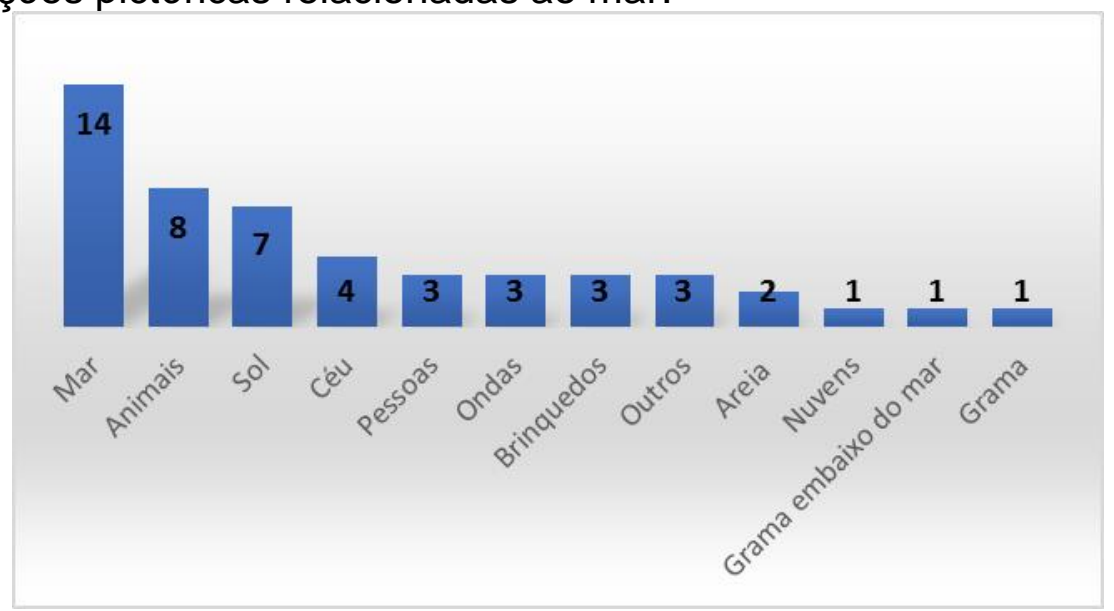

Figura 1: Elementos presentes nos desenhos sobre o mar. Fonte: A pesquisa.

E que pese o fato de $87,5 \%$ dos alunos representarem o mar, dois deles não o desenharam especificamente. Em relação aos animais, houve um elevado percentual de desenhos que os incluíram (50\%), no entanto, as espécies representadas foram peixes, estrela do mar, tartaruga, baleira, lontra, golfinho, caracol e tubarão, ou seja, animais que dificilmente eles visualizaram diretamente na natureza.

Não foram desenhadas tatuíras, águas-vivas, mariscos ou siris que quase diariamente encontramos no litoral do sul do Brasil. Este fenômeno pode ser explicado parcialmente pelo fato de se constituirem as crianças, preponderantemente de famílias de baixa ou média renda e, portanto, a maior parte possui reduzido contato direto com o mar que dista em torno de $150 \mathrm{~km}$ da cidade.

Houve ainda uma consistente associação entre mar e sol e, em menor grau, com o céu, representados, respectivamente, por $43,8 \%$ e $25 \%$, caracterizando a associação do mar com experiências ao ar livre.

Ausentes nos desenhos a representação de mares bravios, de ambientes rochosos e de demais paisagens associadas ao mar em outros contextos, assim como há uma vinculação ao lúdico representado pelo lazer que a praia proporciona à população da região metropolitana de Porto Alegre capital do Rio Grande do Sul. A ludicidade foi associada também ao surgimento nos desenhos de pessoas, ondas e brinquedos (18,8\%), elementos encontrados no ambiente de praia. Considerou-se como categoria "outros" os 
seguintes elementos: flores, coração e casa, representados apenas por um estudante cada um.

Curiosamente, a areia apareceu apenas nos desenhos de dois alunos, algo que contrastou com as ocorrências deste elemento nas atividades anteriores vinculadas ao pátio da escola.

Houve um diálogo com a turma a fim de compreender melhor sua percepção sobre o Mar, o que os alunos sabiam a respeito dele, se o percebiam como parte da natureza. Quando questionados os alunos responderam:

- "O mar é um azul!";

- "Lá tem areia e tubarão, estrela do mar e peixes, tem baleia também!";

- "No mar tem golfinho"; lá fundo";

- "O mar é parte da natureza porque ele tem vários bichos interessantes

- "Também tem tartaruga";

- "O mar é limpo e de noite é sujo, meu irmão disse que devem ser os peixes que limpam o mar!”.

Foi possível notar nas falas dos alunos que eles associaram diretamente o mar com a vida lá existente, representada por alguns animais que foram citados por eles, demostrando que compreendem que no mar vivem diferentes formas de vida. Ao integrar os dados quantitativos com os qualitativos oriundos das falas dos estudantes é possível compreender melhor a relevância dos animais na percepção das crianças, algo que não estava explicitamente conspícuo pelas frequências de elementos dos desenhos (CRESWEEL; PLANO CLARK, 2011; DAL-FARRA; FETTERS, 2017)..

Tais vinculações estão melhor representadas nas falas dos estudantes do que nas epresentações pictóricas, evidenciando que, ao proporcionar um espaço para que o estudante protagonize o processo e explicite as suas noções de ambiente podemos verificar de forma mais acurada o seu olhar sobre a natureza.

Com relação à poluição no mar, as crianças acreditavam ser os peixes os responsáveis pela limpeza do mesmo, não associando o ser humano como causador do impacto ambiente nas praias se constituindo em alerta para a construção de atividades com a dimensão ambiental na educação infantil.

Foi possível notar que a percepção dos alunos a respeito do mar está mais fortemente relacionada com animais marinhos, que aparecem com frequência também em suas falas. Relevante ainda foi o fato das crianças se identificarem nos seus desenhos, embora em uma pequena parcela deles, bem como representar os seus familiares no ambiente em questão. Tais resultados corroboram a relevância de trabalharmos as Ciências da Natureza na educação infantil, assim como os benefícios dos desenhos para tais práticas educativas (TUNICLIFFE; REIS, 2000; WEISMANN, 2004). 
Nota-se que, ao levarem em consideração o ambiente marinho, além dos animais, como visto anteriormente, "sol" (43,8\%), "brinquedos" $(18,8 \%)$, "céu" $(25 \%)$ e "ondas" $(18,8 \%)$ apareceram em seus desenhos, visto que a praia é um local mais frequentado no verão, estação que se relaciona diretamente ao céu ensolarado.

Estes dados nos possibilitam constatar também que a categoria "areia", para os alunos, está muito mais relacionada com seu dia a dia, por estar presente em sua escola, do que com o ambiente da praia e tem uma forte conotação de espaço de lazer e brincadeiras assim como os brinquedos do "playground" (ROCHA et al., 2015).

A seguir os dados do segundo desenho realizado neste encontro. A Figura 2 expõe os desenhos dos alunos expressando o deserto segundo suas perspectivas.

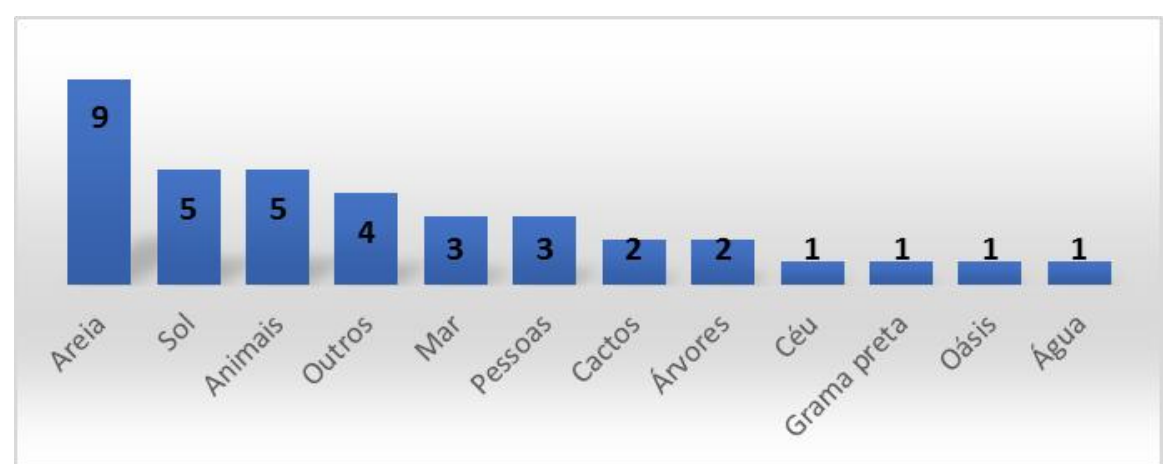

Figura 2: Elementos presentes nos desenhos sobre o deserto.

Fonte: A pesquisa.

Analisando os dados acima, ressaltamos que, ao pensarem no ambiente do deserto, os alunos primeiramente fizeram associação deste com a "areia" $(56,3 \%)$, demonstrando o conhecimento prévio de que este elemento constitui a maior área do deserto. As crianças representaram a seguir o "sol" e "animais" como camelo, barata e caranguejo (31,3\%), assim como, em "outros", uma bola, "coisas que caminham", um coração e um "jet sky".

Um percentual de $18,8 \%$ dos alunos desenhou o mar como componente existente no deserto, possivelmente pelo fato de os alunos terem realizado o desenho no mar nesta mesma etapa que a representação do deserto, ou, algo que pode ser futuramente aprofundado, por realizarem uma associação entre a areia do mar e a areia do deserto.

Os seres humanos foram representados pelo mesmo percentual de estudantes do que no mar $(18,8 \%)$, no entanto, sem que os estudantes representassem a si mesmos ou a sua família, distinguindo a praia como espaço de lazer, do deserto.

Ressalta-se, o contínuo e preponderantemente presente processo de representação conjugada de aspectos vistos, provavelmente "in loco" pelos estudantes, com outros elementos iconizados pela cultura midiática e que 
estão associados ao imaginário das crianças como presentes em cada ambiente, tais como o oásis e o camelo no deserto, assim como os cactos $(12,5 \%)$. O céu foi representado apenas por um aluno, diferentemente do que ocorreu no desenho do mar, aludindo a uma possível indicação da praia como um espaço visitado e de convivência ao ar livre, tal como comumente realizado pelos moradores do Rio Grande do Sul no verão. Quando questionados sobre o deserto, responderam:

- "O deserto é muito quente";

- "E tem que tomar água";

- "No deserto não tem água, sabia?";

- "É todo seco e tem cactos";

- "Tem a múmia";

- "Tem camelo";

- "O deserto não faz parte da natureza porque lá não tem bichos";

- "Cactos tem espinho e é verde"

A integração dos componentes quantitativos e qualitativos (CRESWELL; PLANO CLARK, 2011; DAL-FARRA; FETTERS, 2017) proporcionou compreender que, mesmo com uma parcela da turma não identificando formas de vida no deserto, apesar deste ser conhecido pelo clima árido, ainda houve discordâncias por menções de outros cujas afirmações indicavam que lá não haveria animais, e desta forma o caracterizaram como um local que interessantemente não pertenceria à natureza. Ou seja, a presença de uma associação entre a presença de animais e "ser natureza".

Com relação aos elementos bióticos representados nos desenhos dos alunos, a categoria mais representada foi "animais", visto que $38 \%$ dos alunos a desenhou. A categoria "cactos/árvores" foi representada por $25 \%$ dos alunos, sugerindo que a maior parte dos alunos percebem o deserto com um ambiente arenoso, ensolarado e quente, caracterizando os distintos olhares das crianças em relação aos elementos naturais (TUNICLIFFE; REIS, 2000; WEISMANN, 2004). A Figura 3 mostra a representação dos desenhos dos alunos relacionados à Mata. Observou-se no gráfico acima que $43,8 \%$ dos alunos desenharam elementos sem relação com o tema solicitado, classificados dentro da categoria "outros": "circo", "batatas", "brinquedos", "fantasma", "casa de borboleta" e "coração".

Revista brasileira

educação

ambiental 


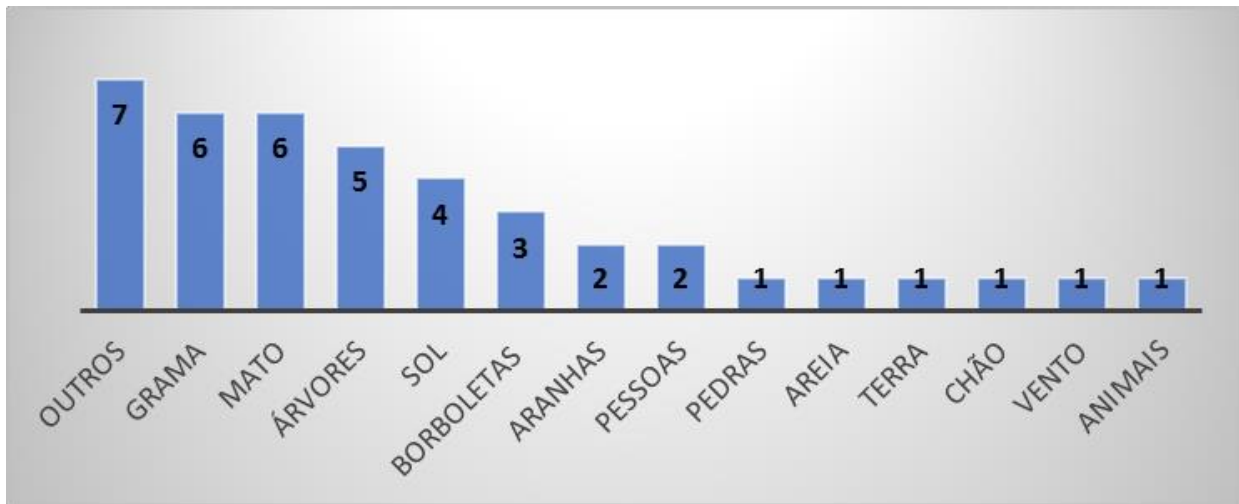

Figura 3: Elementos representados nos desenhos sobre a mata.

Fonte: A pesquisa.

Interessante observar as diferenças nas representações da vegetação identificando a riqueza dos saberes dos alunos em relação a esses aspectos, tal como mata $(37,5 \%)$, árvores $(31,3 \%)$ e mesmo a frequentemente citada pelos estudantes nos outros desenhos, ou seja, a grama $(37,5 \%)$ que representa uma forma que podemos dizer "urbanizada" de vegetação, sendo que um dos estudantes qualificou a mata como:

- "Tem um monte de grama gigante".

Os animais foram escassamente representados, à exceção das borboletas (18,8\%) e aranhas (12,5\%). Quando questionadas sobre a mata, desta vez, as crianças participaram pouco:

- "Tem sapo na mata";

- "Tem aranha";

- "Também tem borboleta";

- "Tem muitas árvores".

Em relação a este desenho, a reduzida participação nas falas e a maior dispersão nos desenhos pode estar relacionado ao fato de esta ter sido a última atividade do encontro. Desta forma, pelo fato de já estarem dispersos e pouco concentrados no tema, desfocaram da atividade desenhando elementos sem relação com o que foi solicitado. Ainda assim, uma parcela dos alunos associou a mata com pequenos artrópodes e com a vegetação, sem que lembrassem especificamente por vertebrados, à exceção do sapo por um dos estudantes.

Desta forma, torna-se necessário levar em conta o processo metodológico envolvido nas práticas educativas bem como salienta-se a crucial observância do planejamento das ações com os estudantes (BRASIL, 1995; 2010). Ao ampliar as possibilidades de construir práticas educativas a respeito da natureza considerando as características dos estudantes e seu contexto, torna-se possível atingir os objetivos educacionais propostos no planejamento. 
A Figura 4 corresponde ao quarto encontro. Neste dia a atividade realizada com os alunos participantes da pesquisa foi referente à percepção deles quanto a chuva.

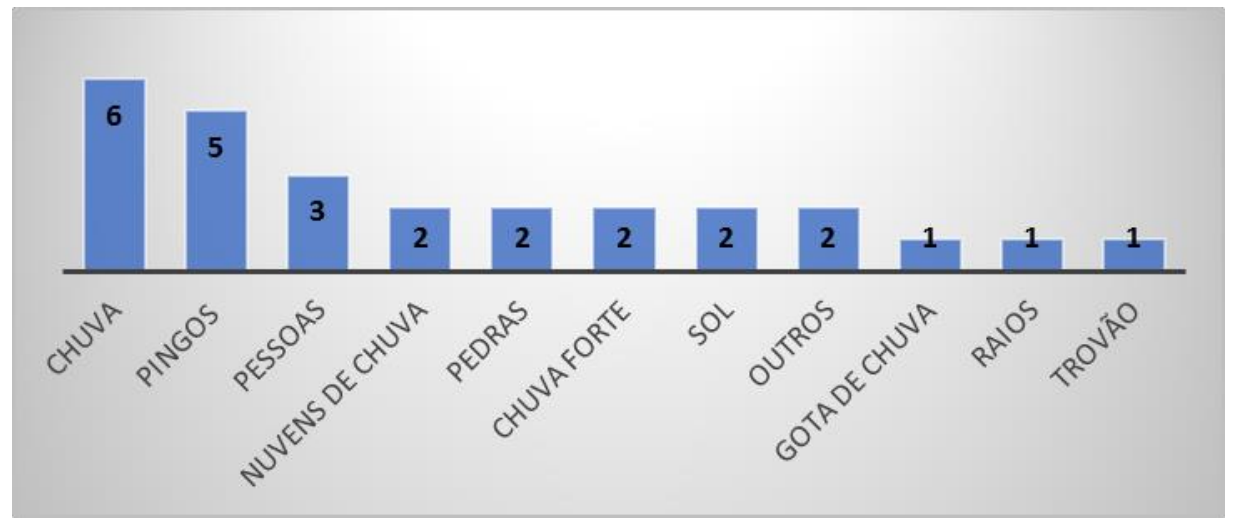

Figura 4: Elementos presentes nos desenhos sobre a chuva.

Fonte: A pesquisa

Verifica-se nos desenhos e, principalmente, nas falas dos alunos, que a chuva foi representada de múltiplas formas pelos estudantes. Seja simplesmente como chuva $(37,5 \%)$, pingos $(31,25 \%)$, chuva forte $(12,5 \%)$ ou gota de chuva representada por um aluno. Alguns alunos desenharam as "pessoas" das suas famílias tomando banho de chuva $(18,75 \%)$ indicando a ludicidade como um aspecto importante.

As representações explícitas do céu apareceram como permeado por nuvens carregadas de chuva, embora curiosamente em número igual às representações do sol.

Dentro da categoria "outros" estão os elementos "caverna" e "pato", havendo ainda as representações de "raios" e "trovões". Em diálogo com os alunos foram questionados sobre a chuva e suas respostas foram as seguintes:

- "É uma coisa que pinga e molha a gente";

- "Molha a areia, as árvores...";

- "A chuva é feita de céu porque vem do céu";

- "É uma nuvem de chuva";

- "A chuva é azul";

- "Não, é branca!";

- "Sabia que caiu pedra do céu?";

- "A minha casa alagou tudo dentro";

- "Ela cai nas folhas";

- "A chuva molha as plantas";

- "A chuva molha a árvore para ela ficar crescendo e crescendo...";

- "Sim, é da natureza porque ela faz as plantas crescerem!" 
Era esperado, neste dia de trabalho, por se tratar de uma escola com uma parcela de alunos que sofrem frequentemente com alagamentos de suas habitações, que as crianças representassem a chuva de uma forma negativa ou, até mesmo, destrutiva, porém, nenhuma representação deste tipo foi feita. No momento de conversa com a turma, dois alunos mencionaram pedras caindo do céu e outro que teve a casa alagada pela chuva, porém, no momento do desenho estas recordações não foram apresentadas.

Percebe-se também, através das falas, que os alunos associaram a chuva com a natureza, diante da necessidade dela para o crescimento das plantas, elemento fundamental ao ser trabalhado na relação entre os elementos abióticos e bióticos e gerando um olhar integrador das inter-relações entre esses aspectos, mesmo que tais interações possam ser mais difíceis para a compreensão de estudantes da educação infantil.

Palácios et al., (2011) trabalhando com estudantes dos anos finais do ensino fundamental abordaram estas inter-relações entre diferentes elementos constituintes de um sistema, demonstrando a viabilidade e, principalmente, a relevância de compreender esses aspectos por parte dos estudantes.

Analisando os desenhos de forma conjunta, observa-se que os seres humanos foram representados em um percentual reduzido dos desenhos (18,8\% para deserto e mar e $12,5 \%$ para mata). Índices semelhantes foram obtidos quando os estudantes desenharam o pátio da escola antes e depois de uma visita (ROCHA et al., 2015) e a praça da escola (ROCHA et al., 2016).

Tal aspecto pode ser problematizado em estudos futuros no sentido de analisar se o fenômeno decorre da usual consideração na cultura contemporânea do ser humano se considerar como "fora do ambiente" assim como assinala-se a proficuidade de abordar a questão ambiental com base em ações integradas e contextualizadas, especialmente com atividades "outdoor" (STERN et al., 2014).

O processo de desvinculação do ser humano da natureza se constitui em um dos elementos constituintes do impacto ambiental antrópico considerando, tal como recorrente em discursos de tal ordem, o ambiente como importante por "nos proporcionar oxigênio, água, alimentos" (MILLER, 2005; GRÜN, 2011; LOUREIRO, DAL-FARRA, 2018).

Conduzindo o olhar para o extremo, uma ética antropocêntrica que vigora há muitos séculos considera o ser humano como possuidor do "objeto" natureza, situando-se fora dessa natureza e capaz de interferir nos sistemas componentes da natureza (PROENÇA et al., 2013). Tais processos corroboram outros estudos que advogam pela importância da articulação entre os desenhos e as Ciências da Natureza na construção de saberes ambientais (TUNICLIFFE; REIS, 2000; ROCHA et al., 2015). 


\section{Considerações Finais}

Depreende-se do estudo em questão e suas características processuais que o olhar dos alunos em relação ao ambiente natural pode ser ampliado por meio de práticas educativas realizadas com a produções de representações pictóricas sobre diferentes espaços do ambiente natural e suas interfaces com o ambiente construído.

Mais especificamente, ao representar ambientes preponderantemente conhecidos por meio de imagens de mídia impressa e eletrônica, foi observada a presença de regularidades interessantes nos desenhos, tais como ícones popularmente reconhecidos de tais locais, tais como os cactos no deserto, assim como ausências de elementos cuja relevância proporcione que sejam trabalhados em sua maior amplitude na escola. Estes aspectos foram melhor analisados e compreendidos a partir da integração dos aspectos quantitativos $e$ qualitativos.

Diante de um meio cada vez mais destituído de elementos bióticos nativos do local, ou mesmo exóticos, foi possível observar, inicialmente, um conjunto restrito de componentes ambientais, porém, ao trabalhar com os desenhos e as falas dos alunos a respeito deles, notamos que principiava uma maior familiaridade com a natureza.

No presente estudo, a continuidade das práticas educativas analisadas tem demonstrado que urge uma maior proximidade das crianças com 0 ambiente natural da cidade que habitam e, também, dos elementos naturais próximos a elas, seja nos espaços escolares, ou em áreas próximas, buscando o desenvolvimento de um olhar mais sensível em relação aos efeitos antrópicos e possíveis impactos deles decorrentes, dialogando sobre 0 ambiente e compreendendo como ele funciona.

Diante da complexidade envolvida nas questões técnicas atinentes a cada área do conhecimento, torna-se crucial o desenvolvimento de práticas educativas que possam realizar a transposição didática de assuntos cuja aridez acadêmica pode afastar os futuros professores de abordá-los em suas aulas. $\mathrm{Na}$ condição de formadores, somos aptos no âmbito da educação a construir tais práticas e elaborar possibilidade efetivas de formação continuada para os profissionais que laboram na Educação Infantil que se constitui em suporte para o desenvolvimento futuro adulto do estudante. Torna-se cada vez mais necessário instigar as percepções das crianças em relação ao ambiente em que vivem a compreender as nuances que brotam de um olhar mais acurado em relação aos elementos abióticos e bióticos que o compõem.

Tais aspectos podem ser trabalhados coadunados com as temáticas comumente estudadas na educação infantil, seja por meio da Matemática, das Linguagens em geral, ou mesmo de atividades cujas fronteiras disciplinares possam estar ausentes, já que tudo se encontra no ambiente, basta que o aluno esteja sensibilizado e instrumentalizado para compreender as interfaces entre ele o entorno em que vive. 


\section{Agradecimentos}

O presente trabalho foi realizado com apoio da Coordenação de Aperfeiçoamento de Pessoal de Nível Superior - Brasil (CAPES) - Código de Financiamento 001.

\section{Referências}

BRASIL. Secretaria de Educação Fundamental. Parâmetros curriculares nacionais: terceiro e quarto ciclos: apresentação dos temas transversais. Brasília: MEC/SEF, 1998. p. 436.

BRASIL. Ministério da Educação e do Desporto. Secretaria de Educação Fundamental. Referencial curricular nacional para a educação infantil. Brasília, DF, MEC/SEF, 1998.

BRASIL. Lei no 9. 795, de 27 de abril de 1999. Dispõe sobre a Educação Ambiental, institui a Política Nacional de Educação Ambiental e dá outras providências. Brasília, DF,

BRASIL. Ministério da Educação. Secretaria de Educação Básica. Diretrizes curriculares nacionais para a educação infantil. Brasília: MEC, SEB, 2010.

BRASIL. Diretrizes Curriculares Nacionais para a Educação Ambiental. Brasília, DF, PARECER CNE/CP no: 14. 2012.

CARRARO, G. Agrotóxico e Meio Ambiente: Uma Proposta de Ensino de Ciências e Química. Porto Alegre, 1997. Disponível em: $<$ http://www.quimica.seed.pr.gov.br/arquivos/File/AIQ 2011/agrotoxicos ufrgs.p df> Acesso em: 23 de julho. 2016.

CARVALHO, I.C.M. Educação Ambiental: a formação do sujeito ecológico. São Paulo: Cortez, 2006.

CHEVALLARD, Y. La transposición didáctica: del saber sabio al saber enseñado. Buenos ]aires: AIQUE, 1998.

CLÉMENT, P. Didactic Transposition and KVP Model: Conceptions as Interactions Between Scientific knowledge, Values and Social Practices. ESERA Summer School, Minho, Braga, Proceedings, p.9-18, 2006. CRESSWELL, J.W.; CLARK, V.L.P. Designing and Conducting Mixed Methods Research. Thousand Oaks: SAGE Publications, 2nd edition, 2011.

DAL-FARRA, R.A.; FETTERS, M.D. Recentes avanços nas pesquisas com métodos mistos: aplicações nas áreas de Educação e Ensino. Acta Scientiae, v. 19, n. 3, p. 466-492, 2017.

DAL-FARRA, R.A.; VALDUGA, M.A Educação Ambiental na formação continuada de professores: as práticas compartilhadas de construção. Linhas Críticas, v. 18, p. 395-415, 2012.

FANARO, M.A.; OTERO, M.R.; GRECA, I.M. Las imágenes en los materiales educativos: las ideas de los professores. Revista Electrónica de Enseñanza de las Ciencias, v. 4., n. 2, 2005. 
GRÜN, M. Ética e Educação Ambiental: a conexão necessária. Campinas: Papirus, 2011.

LOPES, L. A. et al. As Concepções Sobre Insetos no Ensino Fundamental em Escola Pública de Sapucaia do Sul. Acta Scientiae, v. 16, p. 214-233, 2014.

LOUREIRO, J.O.; DAL-FARRA, R.A. Botany and environmental education in elementary school in Brazil: articulating knowledge, values, and procedures. Environmental Education Research, v. 24, n. 12, 2018.

LOUV, R. Last child in the woods. Nova York: Algonquin Paperbacks, 2008.

MILLER, J.R. Biodiversity conservation and the extinction of experience. Trends in Ecology and Evolution, v. 20, n. 8, 2005.

MORAES, R. Ciências para séries iniciais e alfabetização. Porto Alegre. Sagra: DC Luzzatto, 1992.

OTERO, M.R.; GRECA, I.M.; SILVEIRA, F.L. Imágenes visuales en el aula y rendimiento escolar en Física: un estudio comparativo. Revista Electrónica de Enseñanza de las Ciencias, v. 2. n. 1. P. 1-30, 2003.

PAIVA, J.R. Representações Pictóricas no ensino de física moderna: uma construção dos alunos. 2010. 206f. Dissertação (Mestrado) - Faculdade de Educação, Universidade de São Paulo, São Paulo, 2010.

PALÁCIOS, C.M.; DAL-FARRA, R.A.; GELLER, M. Concepções Sistêmicas na Educação Ambiental: uma experiência com alunos do ensino fundamental. Revista Brasileira de Pesquisa em Educação em Ciências, v. 1, p. 211-229, 2011.

PLATAFORMA AGENDA 2030. Disponível em: $<$ http://www.agenda2030.org.br/>. Acesso em 20 de fev. de 2021.

PROENÇA, M.S.; DAL-FARRA, R.A.; OSLAJ, E.U.Native anda exotic species and enviromental education. In: 7th World Environmental Education Congress, Proceedings, 2013, Marrakech. 7th World Environmental Education Congress.

ROCHA, A.G.S. GHENO, S.R.; GONÇALVES, F.C.L.; DAL-FARRA, R.A. Educação infantil. Articulando a produção de desenhos com a Educação Ambiental em uma escola comunitária do sul do Brasil. Revista Iberoamericana de Educação, v. 72, 183-206, 2016.

ROCHA, A.G.S.; GHENO, S.R.; LOUREIRO, J.; DAL-FARRA, R. A. School Backyard Drawings by Kindergarten Students: An Interdisciplinary Experience in the South of Brazil. Creative Education, v. 06, p. 2136-2140, 2015.

STERN, M.J.; POWELL, R.B.; HILL, D. Environmental education program evaluation in the new millennium: what do we measure and what have we learned? Environmental Education Research, v. 20, n. 5, p. 581-611, 2014.

TUNNICLIFFE, S. D.; REISS, M. J. 2000. Building a model of the environment: how do children see plants? Journal of Biological Education, n. 34, p. 172177, 2000.

WEISSMANN, H. Didática das ciências naturais: contribuições e reflexões. Porto Alegre: ArtMed, 2004. 